\title{
Association between miR-137 polymorphism and risk of schizophrenia: a meta-analysis
}

\author{
M.L. Ou ${ }^{1,2 *}$, G. Liu ${ }^{4 *}$, D. Xiao ${ }^{1}$, B.H. Zhang ${ }^{1}$, C.C. Guo ${ }^{1}$, X.G. Ye ${ }^{1}$, Y. Liu ${ }^{1}$, \\ N. Zhang ${ }^{1}$, M. Wang ${ }^{1}$, Y.J. Han ${ }^{1}$, X.H. Ye ${ }^{1}$, C.X. Jing ${ }^{1,3}$ and G. Yang ${ }^{2,3}$ \\ ${ }^{1}$ Department of Epidemiology, School of Medicine, Jinan University, \\ Guangzhou, Guangdong, China \\ ${ }^{2}$ Department of Parasitology, School of Medicine, Jinan University, \\ Guangzhou, Guangdong, China \\ ${ }^{3}$ Key Laboratory of Environmental Exposure and Health in Guangzhou, \\ Jinan University, Guangzhou, Guangdong, China \\ ${ }^{4}$ Shenzhen Center for Disease Control and Prevention, Shenzhen, Guangdong, \\ China \\ *These authors contributed equally to this study. \\ Corresponding authors: G. Yang / C.X. Jing \\ E-mail: guangyangphd@gmail.com / jcxphd@gmail.com \\ Genet. Mol. Res. 15 (3): gmr.15038703 \\ Received April 8, 2016 \\ Accepted June 7, 2016 \\ Published September 16, 2016 \\ DOI http://dx.doi.org/10.4238/gmr.15038703
}

Copyright (C) 2016 The Authors. This is an open-access article distributed under the terms of the Creative Commons Attribution ShareAlike (CC BY-SA) 4.0 License.

ABSTRACT. miR-137, a brain-enriched microRNA, is involved in the control of neuronal proliferation, differentiation, and dendritic arborization, all of which are important for proper neurogenesis and relevant to schizophrenia. miR-137 is also known to regulate many genes implicated in schizophrenia risk. Although reports have associated the miR-137 polymorphism rs1625579 with this disease, their results have been inconsistent. The aim of this meta-analysis was to evaluate the relationship between rs 1625579 and schizophrenia. Data were obtained from an electronic database, and pooled odds ratios (ORs) with 95\% 
confidence intervals $(95 \% \mathrm{CI})$ were used to test the association using the RevMan 5.3 software. Twelve case-control studies comprising 11,583 cases and 14,315 controls were included. An estimated lambda value of 0.46 was recorded, suggesting that a codominant model of inheritance was most likely. A statistically significant association was established under allelic ( $\mathrm{T}$ vs $\mathrm{G}: \mathrm{OR}=1.15,95 \% \mathrm{CI}=1.10-1.21, \mathrm{P}<0.001)$ and homogeneous codominant models (TT vs GG: $\mathrm{OR}=1.32,95 \% \mathrm{CI}=$ 1.13-1.54, $\mathrm{P}<0.001$ ), but no such relationship was detected using the heterogeneous codominant model $(\mathrm{GT} v s \mathrm{GG}$ : $\mathrm{OR}=1.14,95 \% \mathrm{CI}=$ $0.97-1.34, \mathrm{P}=0.11)$. This meta-analysis demonstrates that the rs 1625579 miR-137 genetic variant significantly increases schizophrenia risk.

Key words: Schizophrenia; miR-137; Single nucleotide polymorphism; Meta-analysis; Fixed-effect analysis

\section{INTRODUCTION}

Schizophrenia is a severe, chronic psychiatric disorder arising in late adolescence that profoundly affects neural development and disrupts key traits such as cognition and personality (van Os and Kapur, 2009). The median incidence of this disease is reported to be 15.2 per 100,000 people (McGrath et al., 2008), and its median lifetime prevalence is estimated at 480 per 100,000 patients (Simeone et al., 2015). Moreover, schizophrenia is a major cause of disability (Warner, 2009), with approximately three-quarters of patients suffering an ongoing disability with relapses (Smith et al., 2010).

Schizophrenia is a multifactorial disorder. Although its etiology is unclear, it is widely acknowledged that the development of this disease derives from a combination of genetic and environmental factors (O'Donovan et al., 2003). Some studies have shown that single nucleotide polymorphisms (SNPs) in several genes, such as those encoding vaccinia-related kinase 2 (Zhang et al., 2015), dopamine D2 receptor (Liu et al., 2012), and regulator of G-protein signaling 9 (Zhu et al., 2015) may play major roles in the development of schizophrenia. In addition, the clinical symptoms of schizophrenia are complicated, involving perception, thought, emotion, action, cognitive function, and other faculties. These vary greatly between patients, and even the same individual may exhibit different symptoms at various stages. Analysis of the psychopathological features of various psychotic disorders suggests that symptoms can be clustered into five main categories (van Os and Kapur, 2009). Therefore, if a meaningful molecular marker for schizophrenia screening can be established, at-risk carriers may be identified and corresponding early interventions provided, potentially improving prognosis.

To date, many studies have described the involvement of microRNAs (miRNAs) in nervous system regulation, including neuronal migration and differentiation, synaptic plasticity, and adult neurogenesis (Kosik, 2006). SNPs in genes encoding miRNAs such as miR-206 (rs17578796; Hansen et al., 2007) and miR-30e (rs112439044; Xu et al., 2010) may affect the properties of the transcribed sequences by altering their expression and/or maturation (Saunders et al., 2007), resulting in nervous system disorders such as schizophrenia (Hommers et al., 2015). Notably, the largest schizophrenia genome-wide association study (GWAS) carried out to date found the SNP rs1625579 (G>T), located within an intron of the miR-137 primary transcript, to be associated with this disease (Ripke et al., 2011). Lett et al.

Genetics and Molecular Research 15 (3): gmr.15038703 
(2013) also reported that North American schizophrenia patients carrying the TT genotype of this variant have reduced brain white matter density, diminished hippocampal volume, and increased lateral ventricle volume. However, other studies have not supported an association between miR-137 rs1625579 and schizophrenia or white matter microstructure (Kelly et al., 2014; Rose et al., 2014; Wang et al., 2014). Therefore, no consistent conclusion has been reached regarding the effect of this SNP on schizophrenia. The purpose of this meta-analysis was to explore the relationship between miR-137 rs1625579 and this condition.

\section{MATERIAL AND METHODS}

\section{Identification of eligible studies}

A search of the PubMed, Web of Science, Cochrane Central Register of Controlled Trials, Science Direct, Wiley Online Library, Chinese National Knowledge Infrastructure, and Wanfang Data Resource databases was conducted during August 2015 using the search terms ("miR-137" or "rs1625579") and ("Schizophrenia"), with no limitations placed on language. All references included in the relevant studies were extensively examined for additional publications.

\section{Inclusion and exclusion criteria}

To be included in the present meta-analysis, studies had to: a) evaluate the miR-137 rs1625579 polymorphism in relation to schizophrenia; b) consist of a human case-control study; c) include patients meeting the diagnostic criteria for schizophrenia; as well as d) report detailed genotype data for the calculation of odds ratios (ORs) and $95 \%$ confidence intervals (CIs). The following were excluded from the current analysis: i) studies not based on a case-control design; ii) duplicates of previous publications; iii) abstracts, comments, reviews, posters, and editorials; and iv) reports lacking detailed genotype data. Where multiple investigations used overlapping data, the latest study was included.

\section{Data extraction}

Data for this meta-analysis were extracted according to the Preferred Reporting Items for Systematic Reviews and Meta-Analyses guidelines, with slight modifications. Three investigators (M.L. Ou, D. Xiao, and B.H. Zhang) independently extracted the following data from eligible studies: first author, year of publication, country of origin, ethnicity, number of cases and controls, Hardy-Weinberg equilibrium (HWE) score, and allele and genotype frequencies, amongst other information. Where detailed data were lacking, we attempted to contact the corresponding author to obtain the original dataset. Studies were then excluded if the authors did not provide additional information. Any disagreement between the researchers responsible for extracting data was resolved by consensus. After extraction, the data were reviewed and compared by C.X. Jing.

\section{Quality assessment}

All included studies were assessed according to the Newcastle-Ottawa scale (NOS) criteria (Stang, 2010), which use a "star" rating system to check methodological quality with

Genetics and Molecular Research 15 (3): gmr.15038703 
regard to three aspects: selection, comparability, and exposure. Scores range from zero (low) to nine stars (high). Articles scoring $<5$ were classified as "low quality", and those scoring $\geq 5$ were considered "high quality".

\section{Statistical analysis}

HWE was evaluated among the control groups of each study using the chi-square test. $\mathrm{P}<0.05$ was considered to represent departure from HWE. Pooled ORs and their $95 \% \mathrm{CIs}$ were used to assess the association between miR-137 rs1625579 and susceptibility to schizophrenia under an appropriate model using the RevMan 5.3 software (Cochrane, 2014). Pooled ORs with $Z$-test $\mathrm{P}$ values $<0.05$ were regarded as statistically significant. Statistical heterogeneity among studies was tested by Cochran's $Q$-statistic and the $I^{2}$ metric (Higgins and Thompson, 2002). Values of $I^{2}>50 \%$ and $\mathrm{P}<0.10$ were considered to indicate significant heterogeneity. In the absence of heterogeneity, a fixed-effect model (using the Mantel-Haenszel method) was used; otherwise, a random-effect model (using the DerSimonian and Laird method) was employed. A Begg's funnel plot was generated to assess potential publication bias, and sensitivity analysis was performed with the Comprehensive Meta-analysis software (Biostat Inc., Englewood, NJ, USA).

\section{Per-allele and per-genotype analysis}

In our study, the $\mathrm{T}$ and $\mathrm{G}$ variants were deemed risk and non-risk alleles, respectively. Correspondingly, the TT, GT, and GG genotypes were viewed as mutant homozygous, heterozygous, and wild-type homozygous, respectively. First, we estimated the effect of the risk allele on schizophrenia susceptibility using an allelic model (T $\left.v_{s} \mathrm{G}\right)$. Subsequently, we used the model-free Bayesian approach (Minelli et al., 2005) to estimate genotypic effects as TT vs GG $\left(\mathrm{OR}_{1}\right)$ and GT $v_{s} \mathrm{GG}\left(\mathrm{OR}_{2}\right)$. The parameter lambda $(\lambda)$, defined as the ratio of $\log \mathrm{OR}_{2}$ to $\log \mathrm{OR}_{1}$, was used to gauge the genetic mode of inheritance. Lambda values range from 0 to $1: \lambda=0$ suggests a recessive model (TT $v_{s} \mathrm{GT}+\mathrm{GG}$ ); $\lambda=1$, a dominant model $(\mathrm{GT}+\mathrm{TT} v s \mathrm{GG})$; and if $\lambda=0.5$, a codominant model (TT $v_{s} \mathrm{GG}$; GT $\left.v_{s} \mathrm{GG}\right)$ is implied. If $\lambda>$ 1 or $<0$, then a homozygous or heterosis model is likely, although such cases are rare (Minelli et al., 2005). WinBUGS 1.4.3 (University of Cambridge, England, UK) was used with vague prior distributions for estimation of parameters (i.e., $\lambda$ and ORs). Models were run with a burn-in of 1000 iterations, followed by 10,000 iterations for parameter estimates.

\section{RESULTS}

\section{Characteristics of eligible studies}

In total, 371 relevant studies were retrieved in the initial search. Following screening, 272 records were excluded, of which 66 were duplicates, 159 irrelevant to the topic, and 47 were posters, comments, or abstracts. Thus, 99 published articles were retained. A further 76 unrelated and non-human studies were excluded by reading titles and abstracts. We then assessed the full texts of the remaining 23 publications, and excluded 11 that lacked key information or case and control data, did not concern rs1625579, or consisted of duplicate data (Figure 1). Twelve case-control studies (Ripke et al., 2011; Lett et al., 2013; Green et al.,

Genetics and Molecular Research 15 (3): gmr.15038703 
2013; van Erp et al., 2014; Guan et al., 2014; Rose et al., 2014; Wang et al., 2014; Ma et al., 2014; Yuan et al., 2015; Strazisar et al., 2015; Kuswanto et al., 2015; Sun et al., 2015) were therefore included in our meta-analysis, comprising 11,583 cases and 14,315 controls. Their general characteristics are listed in Table 1, and corresponding quality scores are given in Table S1. Genotype distributions among the control groups of all studies were consistent with HWE $(\mathrm{P}>0.05)$.

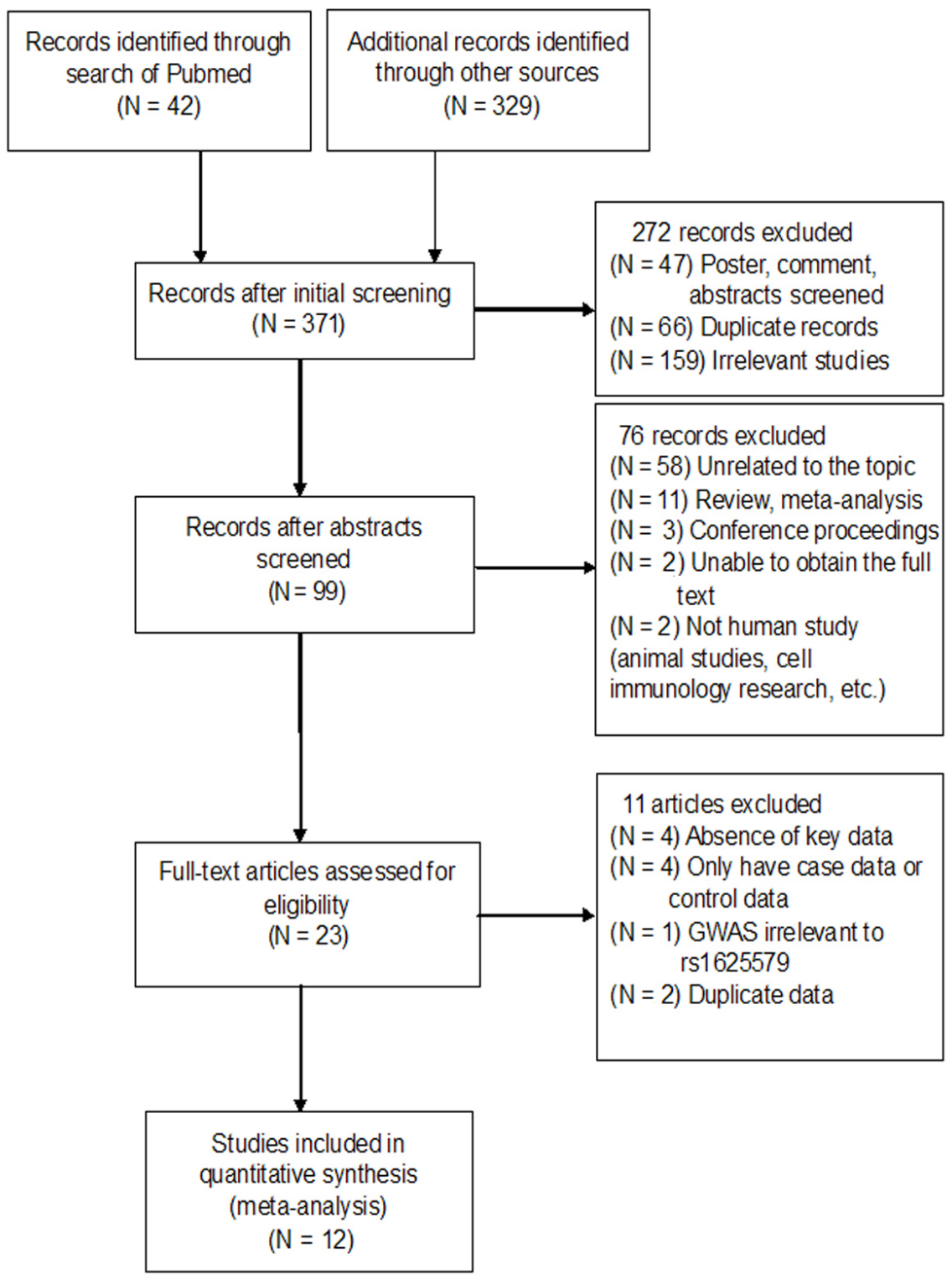

Figure 1. Flowchart showing the identification of relevant studies regarding the relationship between the miR-137 polymorphism of interest and schizophrenia. GWAS = genome-wide association study. 
Table 1. Characteristics of the studies included in the meta-analysis.

\begin{tabular}{|c|c|c|c|c|c|c|c|c|c|c|}
\hline \multirow[t]{2}{*}{ Study } & \multirow[t]{2}{*}{ Country } & \multirow[t]{2}{*}{ Ethnicity } & \multirow{2}{*}{$\begin{array}{c}\mathrm{N} \\
\text { (cases/controls) }\end{array}$} & \multirow{2}{*}{$\begin{array}{c}\text { HWE } \\
(\mathrm{P})\end{array}$} & \multicolumn{3}{|c|}{ Cases } & \multicolumn{3}{|c|}{ Controls } \\
\hline & & & & & GG & GT & TT & GG & GT & TT \\
\hline van Erp et al. (2014) & USA & Caucasian, Black, Asian & $48 / 63$ & $>0.05$ & 0 & 9 & 39 & 2 & 15 & 46 \\
\hline Guan et al. (2014) & China & Asian & $1429 / 1570$ & $>0.05$ & 21 & 297 & 1111 & 38 & 370 & 1162 \\
\hline Rose et al. (2014) & Ireland & Caucasian & $163 / 150$ & $>0.05$ & 2 & 49 & 112 & 4 & 41 & 105 \\
\hline Yuan et al. (2015) & China & Asian & $506 / 520$ & $>0.05$ & 2 & 59 & 445 & 0 & 54 & 466 \\
\hline Lett et al. (2013) & USA, Canada & Caucasian, Non-Caucasian & $510 / 121$ & $>0.05$ & 14 & 152 & 344 & 5 & 40 & 76 \\
\hline Green et al. (2013) & Australia & Caucasian & $491 / 328$ & $>0.05$ & 19 & 153 & 319 & 14 & 109 & 205 \\
\hline Strazisar et al. (2015) & Sweden & Caucasian & $407 / 832$ & $>0.05$ & 21 & 119 & 267 & 44 & 275 & 513 \\
\hline Kuswanto et al. (2015) & China & Asian & $84 / 63$ & $>0.05$ & 1 & 9 & 74 & 2 & 5 & 56 \\
\hline Wang et al. (2014) & China & Asian & $300 / 300$ & $>0.05$ & 0 & 31 & 269 & 0 & 35 & 265 \\
\hline Ma et al. (2014) & China & Asian & $611 / 628$ & $>0.05$ & 2 & 59 & 550 & 5 & 82 & 541 \\
\hline Sun et al. (2015) & China & Asian & $589 / 622$ & $>0.05$ & 5 & 72 & 512 & 3 & 79 & 540 \\
\hline $\mathrm{UK}^{\mathrm{a}}$ & UK & Caucasian & $472 / 2934$ & $>0.05$ & 15 & 137 & 320 & 109 & 914 & 1911 \\
\hline CATIE $^{a}$ & USA & Caucasian & $402 / 207$ & $>0.05$ & 12 & 115 & 275 & 7 & 62 & 138 \\
\hline Aberdeen $^{\mathrm{a}}$ & UK & Caucasian & $720 / 698$ & $>0.05$ & 21 & 202 & 497 & 27 & 222 & 449 \\
\hline Cardiff $^{\mathrm{a}}$ & Bulgaria & Caucasian & $527 / 609$ & $>0.05$ & 17 & 157 & 353 & 30 & 211 & 368 \\
\hline London $^{\mathrm{a}}$ & UK & Caucasian & $518 / 491$ & $>0.05$ & 15 & 145 & 358 & 19 & 157 & 315 \\
\hline Portugal $^{\mathrm{a}}$ & Portugal & Caucasian & $346 / 215$ & $>0.05$ & 7 & 87 & 252 & 6 & 60 & 149 \\
\hline Swedish1 ${ }^{\mathrm{a}}$ & Sweden & Caucasian & $168 / 167$ & $>0.05$ & 6 & 53 & 109 & 9 & 60 & 98 \\
\hline Swedish2 ${ }^{\mathrm{a}}$ & Sweden & Caucasian & $390 / 229$ & $>0.05$ & 17 & 128 & 245 & 13 & 84 & 132 \\
\hline Bonn $^{\mathrm{a}}$ & Germany & Caucasian & $474 / 1304$ & $>0.05$ & 20 & 153 & 301 & 58 & 434 & 812 \\
\hline Copenhagen $^{\mathrm{a}}$ & Denmark & Caucasian & $482 / 457$ & $>0.05$ & 18 & 151 & 313 & 25 & 164 & 268 \\
\hline Munich $^{\mathrm{a}}$ & Germany & Caucasian & $434 / 351$ & $>0.05$ & 16 & 134 & 284 & 15 & 116 & 220 \\
\hline TOP3 $^{a}$ & Norway & Caucasian & $248 / 351$ & $>0.05$ & 11 & 83 & 154 & 15 & 115 & 221 \\
\hline $\mathrm{UCLA}^{\mathrm{a}}$ & Netherlands & Caucasian & $704 / 631$ & $>0.05$ & 21 & 201 & 482 & 26 & 206 & 399 \\
\hline Hillside $^{\mathrm{a}}$ & USA & Caucasian & $192 / 190$ & $>0.05$ & 7 & 54 & 131 & 5 & 52 & 133 \\
\hline Edinburgh $^{\mathrm{a}}$ & UK & Caucasian & $368 / 284$ & $>0.05$ & 11 & 104 & 253 & 9 & 85 & 190 \\
\hline
\end{tabular}

HWE = Hardy-Weinberg equilibrium. ${ }^{\mathrm{a}}$ Genome-wide association study data from Schizophrenia Psychiatric Genome-Wide Association Study (GWAS) Consortium (Ripke et al., 2011).

\section{Association between miR-137 rs1625579 and schizophrenia susceptibility}

As no heterogeneity was detected under any genetic model ( $\mathrm{P}>0.10$ and $\left.I^{2}<50 \%\right)$, the fixed-effect model was used. As shown in Figure 2, there was a statistically significant difference between miR-137 rs1625579 alleles and genotypes in terms of schizophrenia susceptibility under the allelic ( $\mathrm{T} v s \mathrm{G}$ : $\mathrm{OR}=1.15,95 \% \mathrm{CI}=1.10-1.21, \mathrm{P}<0.001)$ and the homogeneous codominant models (TT vs GG: $\mathrm{OR}=1.32,95 \% \mathrm{CI}=1.13-1.54, \mathrm{P}<0.001$ ), but no such association was observed under the heterogeneous codominant model (GT vs GG: OR $=1.14,95 \% \mathrm{CI}=0.97-1.34, \mathrm{P}=0.11) . \mathrm{A} \lambda$ value of $0.46(95 \% \mathrm{CI}=0.028-0.942)$ suggested that a codominant inheritance mode was most likely. Sensitivity analysis (Table S2) showed that removal of any given article did not result in a significant change to the OR, suggesting that our results are reasonably stable.

A stratified analysis based on World Health Organization (WHO) regions (Table S3) revealed the same association under allelic and codominant models in the European region ( $\mathrm{T}$ vs $\mathrm{G}: \mathrm{OR}=1.15,95 \% \mathrm{CI}=1.09-1.22, \mathrm{P}<0.001$; $\mathrm{TT}$ vs $\mathrm{GG}: \mathrm{OR}=1.31,95 \% \mathrm{CI}=1.10-1.58, \mathrm{P}$ $=0.002 ;$ GT $v s$ GG: $\mathrm{OR}=1.12,95 \% \mathrm{CI}=0.94-1.34, \mathrm{P}=0.20)$, but not in the Western Pacific ( $\mathrm{T} v_{\mathrm{S}} \mathrm{G}: \mathrm{OR}=1.17,95 \% \mathrm{CI}=1.04-1.31, \mathrm{P}=0.009 ; \mathrm{TT} v_{s} \mathrm{GG}$ : $\mathrm{OR}=1.49,95 \% \mathrm{CI}=0.95-2.35$, $\mathrm{P}=0.08$; GT vs GG: $\mathrm{OR}=1.28,95 \% \mathrm{CI}=0.80-2.05, \mathrm{P}=0.30)$ or the Americas (T vs $\mathrm{G}: \mathrm{OR}=$ $1.09,95 \% \mathrm{CI}=0.90-1.33, \mathrm{P}=0.36$; TT vs $\mathrm{GG}: \mathrm{OR}=1.20,95 \% \mathrm{CI}=0.66-2.16, \mathrm{P}=0.55$; $\mathrm{GT}$ vs GG: $\mathrm{OR}=1.11,95 \% \mathrm{CI}=0.60-2.03, \mathrm{P}=0.75$ ). This suggests that no clear relationship exists between rs 1625579 and schizophrenia among populations of these latter two regions. 
miR-137 polymorphism and schizophrenia

A
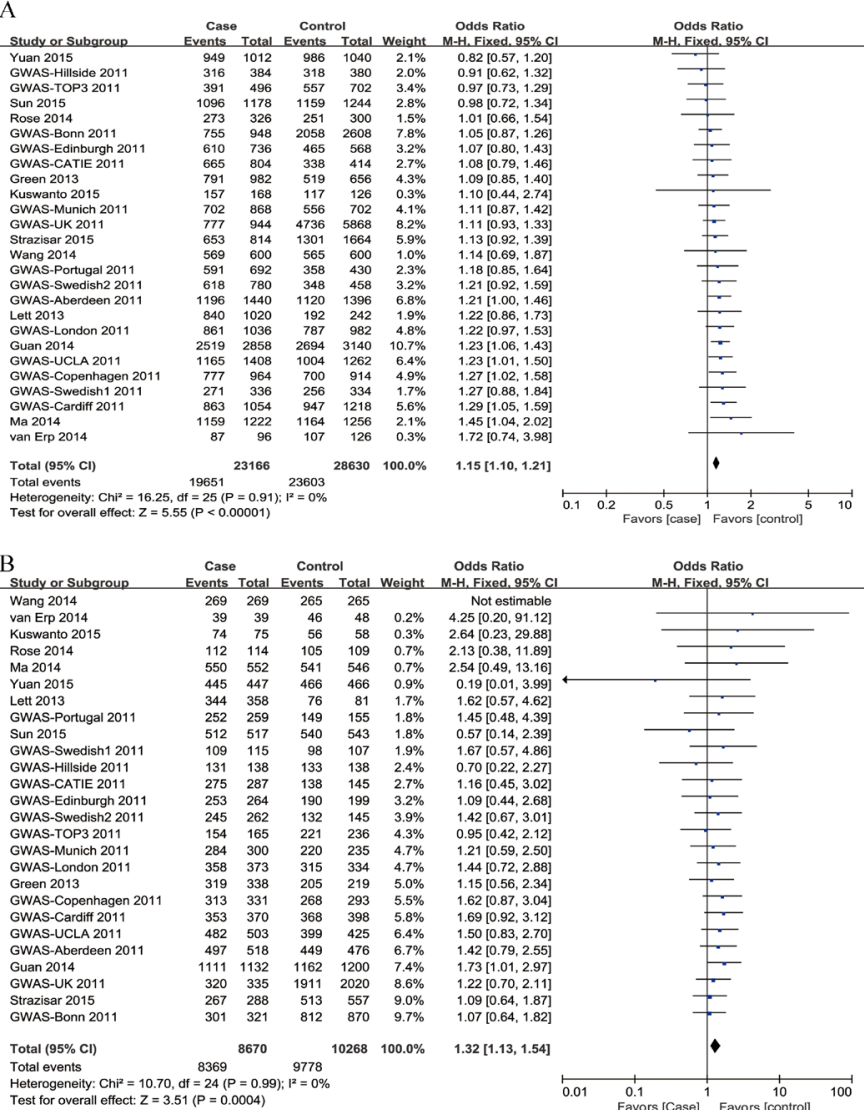

$\mathrm{C}$

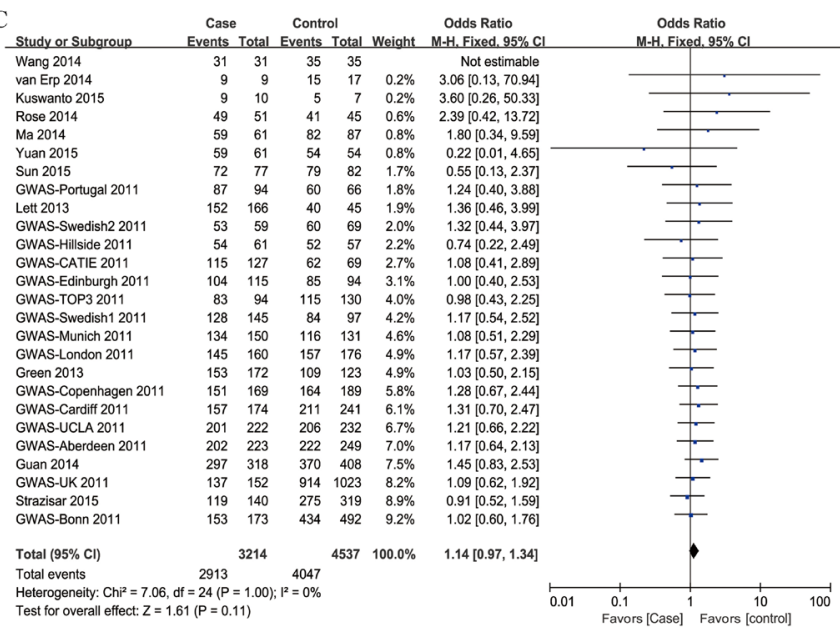

Figure 2. Forest plots concerning the association between miR-137 rs1625579 and schizophrenia. A. Allelic model ( $\mathrm{T} v s \mathrm{G})$. B. Codominant model (TT $v s \mathrm{GG})$. C. Codominant model (GT vs GG). M-H = Mantel-Haenszel; d.f. = degrees of freedom; $\mathrm{CI}=$ confidence interval; $\mathrm{Chi}^{2}=$ chi-square; $\mathrm{GWAS}=$ genome-wide association study .

Genetics and Molecular Research 15 (3): gmr.15038703 


\section{Publication bias}

The shapes of the funnel plots, including all studies, indicated the absence of any potential publication bias under the allelic and codominant models (TT vs GG and GT vs GG; Figure 3).
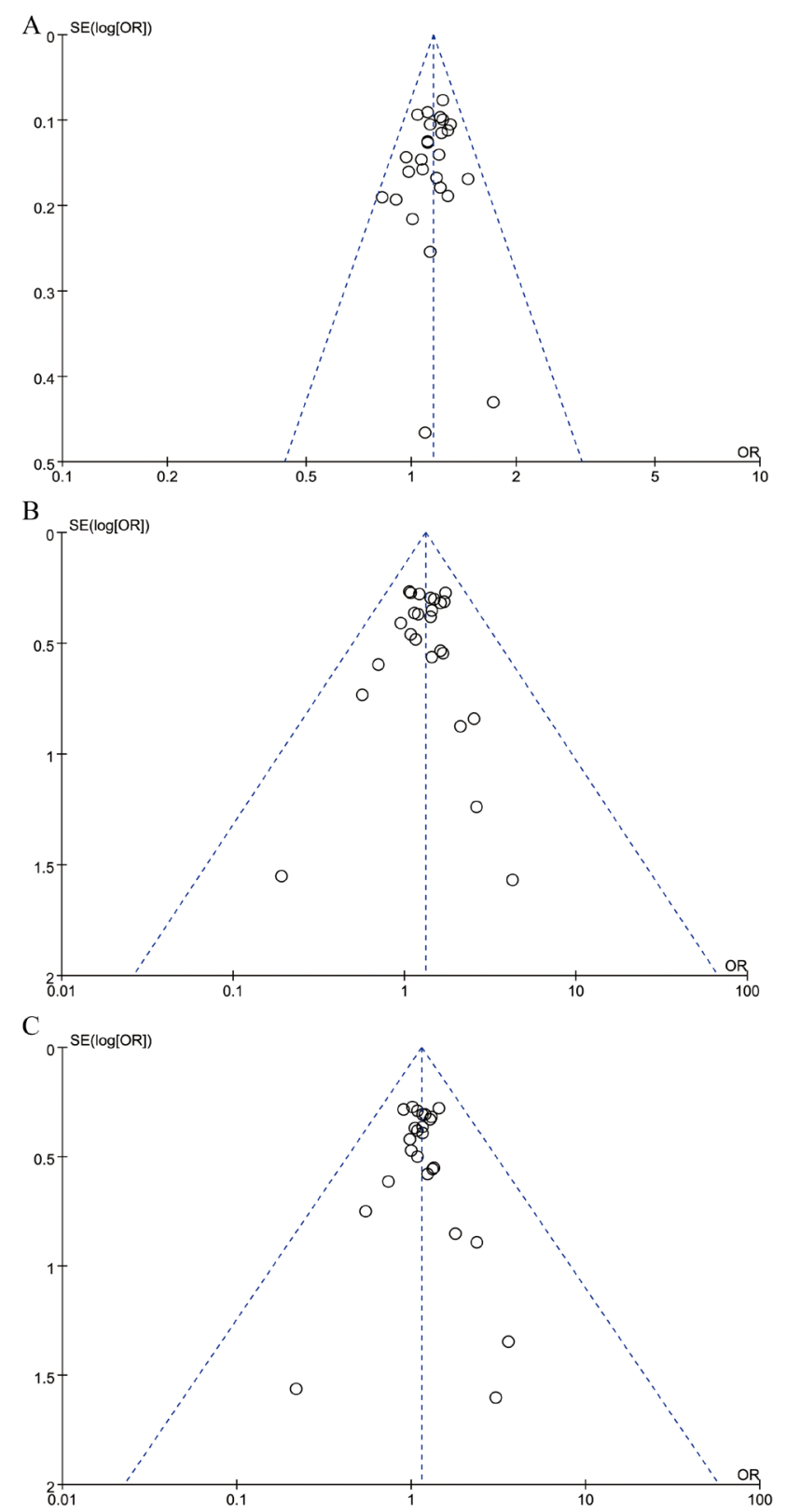

Figure 3. Begg's funnel plot of publication bias. A. Allelic model (T vs G). B. Codominant model (TT vs GG). C. Codominant model (GT vs GG). $\mathrm{SE}=$ standard error; $\mathrm{OR}=$ odds ratio.

Genetics and Molecular Research 15 (3): gmr.15038703 


\section{DISCUSSION}

This meta-analysis aimed to advance our understanding of the association between miR-137 rs1625579 and susceptibility to schizophrenia. Our data demonstrated that this polymorphism is significantly associated with increased schizophrenia risk. Individuals carrying the $\mathrm{T}$ allele had a $15 \%$ increased risk of developing this disease compared to those with the $\mathrm{G}$ allele. In addition, subjects carrying the rs 1625579 TT genotype were at a $32 \%$ greater risk compared to those with the GG genotype. In the stratified analysis according to WHO regions, this same relationship was observed under the allelic and codominant models among studies from countries of the European region, but not in data from the Western Pacific or the Americas. As shown in Table S3, $95 \%$ CIs relating to these latter were wider than those observed using European studies, suggesting insufficient sample sizes for data from the Western Pacific and American regions.

This analysis based on population studies showed that the miR-137 polymorphism increases schizophrenia risk, which might provide some evidence to uncover the major genetic factors involved in the pathogenesis of schizophrenia. Moreover, such variants might serve as useful markers for schizophrenia screening, allowing carriers to be identified and provided with appropriate treatment at an early stage, improving the health mentally and psysically.

miR-137 is known to be a major regulator of the nervous system (Yin et al., 2014). Using bioinformatics, Wright et al. (2013) identified 1144 genes potentially targeted by this miRNA, of which 25 or more intersected with those listed in the SZGR schizophrenia gene resource database. In addition, they identified 26 miR-137-regulated genes associated with susceptibility to this disease. Sun et al. (2011) demonstrated that miR-137, revealed to be a target of TLX (a nuclear receptor transcription factor) and a novel upstream regulator of lysine-specific demethylase 1 (LSD1), forms a regulatory feedback loop with these proteins to maintain the dynamics of neural stem cell (NSC) proliferation and differentiation. TLX is an essential regulator maintaining adult NSCs in an undifferentiated and self-renewable state. It achieves this in part by recruiting and forming a complex with its corepressor LSD1, the first lysyl demethylase found to regulate histone methylation (Shi et al., 2004), before binding an miR-137 genomic region to inhibit methylation of pre-miR-137, thus downregulating expression of miR-137 (Sun et al., 2007, 2010, 2011). Remarkably, as a target of miR-137, expression of LSD1 is in turn inhibited by this miRNA. In addition, it has been shown that increased miR-137 expression leads to reduced NSC proliferation and accelerated neural differentiation in mice (Sun et al., 2011). Thus, miR-137 plays an important role in regulating these processes in NSCs. Moreover, it also participates in the control of signal transduction and neuronal maturation through effects on its target genes.

Neuronal maturation and communication lead to the establishment of functional neural circuits, and abnormalities in neural structure and function can cause brain disorders such as schizophrenia. The SNP rs 1625579 is located in an intron of a primary miR-137 transcript, and may affect the expression or maturation of this miRNA (Saunders et al., 2007), thus resulting in alterations to brain function.

In our meta-analysis, the NOS quality assessment scores of all included studies were no lower than 6 . Furthermore, sensitivity analysis suggested that our results were sufficiently robust, and no significant heterogeneity or publication bias was detected. In addition, this meta-analysis returned results consistent with the largest schizophrenia GWAS conducted. However, the present findings should be interpreted with caution owing to certain limitations.

Genetics and Molecular Research 15 (3): gmr.15038703 
First, all eligible investigations in English or Chinese were incorporated, but those published in other languages that may have met our study criteria were not included. Second, the majority of data were obtained from Asian and Caucasian populations, with black and African individuals being insufficiently represented. Additional studies are needed to investigate the influence of this SNP in other populations. Third, outcomes were based on individual unadjust

In summary, this meta-analysis supports a clear association between the miR-137 rs1625579 SNP and schizophrenia risk. A comprehensive evaluation of gene-gene and geneenvironment interactions should also be performed in future analysis.

\section{Conflicts of interest}

The authors declare no conflict of interest.

\section{ACKNOWLEDGMENTS}

Research supported in part by the National Natural Science Foundation of China (grants \#30901249, \#81101267, \#81541070, \#91543132), the Guangdong Natural Science Foundation (grants \#10151063201000036, \#S2011010002526, \#2016A030313089), the Guangdong Province Medical Research Foundation (grants \#A2014374, \#A2015310), and the Project from Jinan University (grants \#21612426, \#21615426, \#JNUPHPM2016001, \#JNUPHPM2016002).

\section{REFERENCES}

Cochrane (2014). The Cochrane collaboration. Available at [http://www.cochrane.org/]. Accessed June 2014.

Green MJ, Cairns MJ, Wu J, Dragovic M, et al.; Australian Schizophrenia Research Bank (2013). Genome-wide supported variant MIR137 and severe negative symptoms predict membership of an impaired cognitive subtype of schizophrenia. Mol. Psychiatry 18: 774-780. http://dx.doi.org/10.1038/mp.2012.84

Guan F, Zhang B, Yan T, Li L, et al. (2014). MIR137 gene and target gene CACNA1C of miR-137 contribute to schizophrenia susceptibility in Han Chinese. Schizophr. Res. 152: 97-104.http://dx.doi.org/10.1016/j.schres.2013.11.004

Hansen T, Olsen L, Lindow M, Jakobsen KD, et al. (2007). Brain expressed microRNAs implicated in schizophrenia etiology. PLoS One 2: e873.http://dx.doi.org/10.1371/journal.pone.0000873

Higgins JP and Thompson SG (2002). Quantifying heterogeneity in a meta-analysis. Stat. Med. 21: 1539-1558. http:// dx.doi.org/10.1002/sim.1186

Hommers LG, Domschke K and Deckert J (2015). Heterogeneity and individuality: microRNAs in mental disorders. $J$ Neural Transm (Vienna) 122: 79-97.http://dx.doi.org/10.1007/s00702-014-1338-4

Kelly S, Morris DW, Mothersill O, Rose EJ, et al. (2014). Genome-wide schizophrenia variant at MIR137 does not impact white matter microstructure in healthy participants. Neurosci. Lett. 574: 6-10. http://dx.doi.org/10.1016/j. neulet.2014.05.002

Kosik KS (2006). The neuronal microRNA system. Nat. Rev. Neurosci. 7: 911-920. http://dx.doi.org/10.1038/nrn2037

Kuswanto CN, Sum MY, Qiu A, Sitoh YY, et al. (2015). The impact of genome wide supported microRNA-137 (MIR137) risk variants on frontal and striatal white matter integrity, neurocognitive functioning, and negative symptoms in schizophrenia. Am. J. Med. Genet. B. Neuropsychiatr. Genet. 168B: 317-326. http://dx.doi.org/10.1002/ajmg.b.32314

Lett TA, Chakravarty MM, Felsky D, Brandl EJ, et al. (2013). The genome-wide supported microRNA-137 variant predicts phenotypic heterogeneity within schizophrenia. Mol. Psychiatry 18: 443-450.http://dx.doi.org/10.1038/mp.2013.17

Liu ZW, Liu JL, An Y, Zhang L, et al. (2012). Association between Ser311Cys polymorphism in the dopamine D2 receptor gene and schizophrenia risk: a meta-analysis in Asian populations. Genet. Mol. Res. 11: 261-270. http://dx.doi. org/10.4238/2012.February.8.1

Ma G, Yin J, Fu J, Luo X, et al. (2014). Association of a miRNA-137 polymorphism with schizophrenia in a Southern Chinese Han population. BioMed Res. Int. 2014: 751267. http://dx.doi.org/10.1155/2014/751267

Genetics and Molecular Research 15 (3): gmr.15038703 
miR-137 polymorphism and schizophrenia

McGrath J, Saha S, Chant D and Welham J (2008). Schizophrenia: a concise overview of incidence, prevalence, and mortality. Epidemiol. Rev. 30: 67-76. http://dx.doi.org/10.1093/epirev/mxn001

McGuffin P and Gottesman II (1999). Risk factors for schizophrenia. N. Engl. J. Med. 341: 370-371, author reply 372. http://dx.doi.org/10.1056/NEJM199907293410513

Minelli C, Thompson JR, Abrams KR, Thakkinstian A, et al. (2005). The choice of a genetic model in the meta-analysis of molecular association studies. Int. J. Epidemiol. 34: 1319-1328. http://dx.doi.org/10.1093/ije/dyi169

O’Donovan MC, Williams NM and Owen MJ (2003). Recent advances in the genetics of schizophrenia. Hum. Mol. Genet. 12: R125-R133.http://dx.doi.org/10.1093/hmg/ddg302

Picchioni MM and Murray RM (2007). Schizophrenia. BMJ 335: 91-95.http://dx.doi.org/10.1136/bmj.39227.616447.BE

Ripke S, Sanders AR, Kendler KS, Levinson DF, et al.; Schizophrenia Psychiatric Genome-Wide Association Study (GWAS) Consortium (2011). Genome-wide association study identifies five new schizophrenia loci. Nat. Genet. 43 : 969-976. http://dx.doi.org/10.1038/ng.940

Rose EJ, Morris DW, Fahey C, Cannon D, et al. (2014). The miR-137 schizophrenia susceptibility variant rs1625579 does not predict variability in brain volume in a sample of schizophrenic patients and healthy individuals. Am. J. Med. Genet. B. Neuropsychiatr. Genet. 165B: 467-471.http://dx.doi.org/10.1002/ajmg.b.32249

Saunders MA, Liang H and Li WH (2007). Human polymorphism at microRNAs and microRNA target sites. Proc. Natl. Acad. Sci. USA 104: 3300-3305.http://dx.doi.org/10.1073/pnas.0611347104

Shi Y, Lan F, Matson C, Mulligan P, et al. (2004). Histone demethylation mediated by the nuclear amine oxidase homolog LSD1. Cell 119: 941-953.http://dx.doi.org/10.1016/j.cell.2004.12.012

Shorter KR and Miller BH (2015). Epigenetic mechanisms in schizophrenia. Prog. Biophys. Mol. Biol. 118: 1-7. http:// dx.doi.org/10.1016/j.pbiomolbio.2015.04.008

Simeone JC, Ward AJ, Rotella P, Collins J, et al. (2015). An evaluation of variation in published estimates of schizophrenia prevalence from 1990-2013: a systematic literature review. BMC Psychiatry 15: 193. http://dx.doi.org/10.1186/ $\underline{\mathrm{s} 12888-015-0578-7}$

Smith T, Weston C and Lieberman J (2010). Schizophrenia (maintenance treatment). Am. Fam. Physician 82: 338-339.

Stang A (2010). Critical evaluation of the Newcastle-Ottawa scale for the assessment of the quality of nonrandomized studies in meta-analyses. Eur. J. Epidemiol. 25: 603-605. http://dx.doi.org/10.1007/s10654-010-9491-z

Strazisar M, Cammaerts S, van der Ven K, Forero DA, et al. (2015). MIR137 variants identified in psychiatric patients affect synaptogenesis and neuronal transmission gene sets. Mol. Psychiatry 20: 472-481. http://dx.doi.org/10.1038/ $\underline{\mathrm{mp} .2014 .53}$

Sun G, Yu RT, Evans RM and Shi Y (2007). Orphan nuclear receptor TLX recruits histone deacetylases to repress transcription and regulate neural stem cell proliferation. Proc. Natl. Acad. Sci. USA 104: 15282-15287.http://dx.doi. org/10.1073/pnas.0704089104

Sun G, Alzayady K, Stewart R, Ye P, et al. (2010). Histone demethylase LSD1 regulates neural stem cell proliferation. Mol. Cell. Biol. 30: 1997-2005.http://dx.doi.org/10.1128/MCB.01116-09

Sun G, Ye P, Murai K, Lang MF, et al. (2011). miR-137 forms a regulatory loop with nuclear receptor TLX and LSD1 in neural stem cells. Nat. Commun. 2: 529. http://dx.doi.org/10.1038/ncomms1532

Sun YJ, Yu Y, Zhu GC, Sun ZH, et al. (2015). Association between single nucleotide polymorphisms in MiR219-1 and MiR137 and susceptibility to schizophrenia in a Chinese population. FEBS Open Bio 5: 774-778. http://dx.doi. org/10.1016/j.fob.2015.08.008

Suvisaari J (2010). Risk factors of schizophrenia. Duodecim 126: 869-876.

van Erp TG, Guella I, Vawter MP, Turner J, et al. (2014). Schizophrenia miR-137 locus risk genotype is associated with dorsolateral prefrontal cortex hyperactivation. Biol. Psychiatry 75: 398-405. http://dx.doi.org/10.1016/j. biopsych.2013.06.016

van Os J and Kapur S (2009). Schizophrenia. Lancet 374: 635-645.http://dx.doi.org/10.1016/S0140-6736(09)60995-8

Wang S, Li W, Zhang H, Wang X, et al. (2014). Association of microRNA137 gene polymorphisms with age at onset and positive symptoms of schizophrenia in a Han Chinese population. Int. J. Psychiatry Med. 47: 153-168. http://dx.doi. org/10.2190/PM.47.2.f

Warner R (2009). Recovery from schizophrenia and the recovery model. Curr. Opin. Psychiatry 22: 374-380. http://dx.doi. org/10.1097/YCO.0b013e32832c920b

Wright C, Turner JA, Calhoun VD and Perrone-Bizzozero N (2013). Potential Impact of miR-137 and its Targets in Schizophrenia. Front. Genet. 4: 58. http://dx.doi.org/10.3389/fgene.2013.00058

Xu Y, Li F, Zhang B, Zhang K, et al. (2010). MicroRNAs and target site screening reveals a pre-microRNA-30e variant associated with schizophrenia. Schizophr. Res. 119: 219-227. http://dx.doi.org/10.1016/j.schres.2010.02.1070

Yin J, Lin J, Luo X, Chen Y, et al. (2014). miR-137: a new player in schizophrenia. Int. J. Mol. Sci. 15: 3262-3271. http:// dx.doi.org/10.3390/ijms 15023262

Genetics and Molecular Research 15 (3): gmr.15038703 
Yuan J, Cheng Z, Zhang F, Zhou Z, et al. (2015). Lack of association between microRNA-137 SNP rs1625579 and schizophrenia in a replication study of Han Chinese. Mol. Genet. Genomics 290: 297-301. http://dx.doi.org/10.1007/ s00438-014-0924-3

Zhang B, Gao CY, Zhang HB, Yang B, et al. (2015). Association of the VRK2 gene rs3732136 polymorphism with schizophrenia in a Northwest Chinese Han population. Genet. Mol. Res. 14: 9404-9411. http://dx.doi. org/10.4238/2015.August.14.4

Zhu YS, Li YX, Qiao XM and Zhang HB (2015). Regulators of G-protein signaling 9 genetic variations in Chinese subjects with schizophrenia. Genet. Mol. Res. 14: 8458-8465.http://dx.doi.org/10.4238/2015.July.28.13

\section{Supplementary material}

Table S1. Newcastle-Ottawa scale (NOS) scores of the studies included in the meta-analysis.

Table S2. Results of sensitivity analysis.

Table S3. Effect of miR-137 rs1625579 genotypes and alleles on schizophrenia risk, according to World Health Organization region.

Genetics and Molecular Research 15 (3): gmr.15038703 